\title{
Evaluation of Cases Had Stab Wound Injuries, 2013 -
} 2017

\author{
Eren Akgündüz ${ }^{a}, \operatorname{Kenan~Kaya~}^{b}, \operatorname{Kemal~Yılmaz~}^{c}$, Zeynep Şeker $^{c}$, Ahmet Hilal $^{c}$, Necmi Çekin $^{\text {b,c }}$ \\ ${ }^{a}$ Ministry of Justice, Council of Forensic Medicine, Kastamonu, Turkey \\ ${ }^{\mathrm{b}}$ Ministry of Justice, Council of Forensic Medicine, Adana, Turkey \\ ${ }^{\mathrm{c}}$ Department of Forensic Medicine, Cukurova University, Adana, Turkey
}

*Corresponding Author: Kenan Kaya; k_kaya_71@ hotmail.com

Received 26 May 2019;

Accepted 21 June 2019;

Published 27 June 2019

\begin{abstract}
Background: Sharp objects (SO) are widely used today for various purposes in homes and workplaces. These tools are always at hand a solitary appliance or method does not require criminal sanctions unless they are misused, but they are quite often used for attack, self-defense and even to kill. Objective: The injuries and deaths caused by sharp objects have an important place in the practice of forensic medicine. Design: Retrospective review of medical reports. Setting: Auniversity hospital, Turkey. Patients and Methods: A total of 2464 cases with penetrating stab wound, whose forensic report was arranged at the Forensic Medicine Department of Cukurova University Faculty of Medicine between 2013-2017, were examined retrospectively. Results: While $90 \%$ (n: 2219) of the cases were male, 10\% (n:245) were female. The average age was 28.1, the youngest patient was 5 years old and the oldest patient was 88 years old. Total 935 cases (37.9\%) were between 11 and 20 years old, the highest number of cases was seen in July with 298 cases $(12.1 \%)$ and 284 cases $(11.5 \%)$ were exposed to life-threatening conditions. When injuries were examined according to body regions; extremity injuries were in the first place with 1541 cases $(62.5 \%)$. When cases were evaluated in terms of number of lesions; it was detected that single lesion was in the first place with 1479 cases (60\%) and 53.1\% (n:1308) of cases were injured from their left side. Among life-threatening injuries; thorax was in the first place with 118 cases (41.5\%). Conclusions: Injuries due to sharp objects come in the first place among penetrating injuries. Deaths can be seen as a result of injuries they cause in vital organs. Especially the depth of the wound trace, if injury to muscle-fascia is noted on the forensic report is important when it is necessary to decide the weight of injury, problems arise when the " the first examining and treating physician skips detailed identification". It would be appropriate for the physicians involved in emergency intervention to be informed of this.
\end{abstract}

Keywords: sharp objects, forensic report, injury.

\section{Background}

Sharp objects are widely used today for various purposes in homes and workplaces. ${ }^{[1]}$ These tools are always at hand a solitary appliance or method does not require criminal sanctions unless they are misused, but they are quite often used for attack, selfdefense and even to kill. ${ }^{[2]}$ Penetrating stab wounds, are in the first place among penetrating injuries. ${ }^{[3]}$ These tools cause injury to internal organs, veins and extremities. ${ }^{[4,5]}$ Deaths can be seen as a result of injuries they cause in vital organs. ${ }^{[3,6,7]}$ The injuries and deaths caused by the cutting-drilling tool have an important place in the practice of forensic medicine. ${ }^{[8]}$

\section{Patients and Methods}

A total of 2464 cases with penetrating stab wound among 21586 cases, whose forensic report was arranged at the Forensic Medicine Department of Çukurova University Faculty of Medicine between 2013-2017, were examined retrospectively. In this context, gender, age, number of lesions, body area and side (right or left) suffering from trauma, number of cases per month, whether the person is exposed to vital danger or not were examined. The obtained data were converted into graphics and tables.

\section{Results}

A total of 2464 cases $(11.4 \%)$ with penetrating stab wound were observed among 21586 cases, who were consulted for exact report to the Forensic Medicine Department of Cukurova University Faculty of Medicine between 2013-2017. While 90\% (n:2219) of the cases were male, $10 \%$ (n:245) were female. The average age was 28.1, the youngest patient was 5 years old and the oldest patient was 88 years old. In distribution according to age groups; patients between the ages of 11-20 were at first place with 935 cases $(37.9 \%)$ and this was followed by patients between the ages of 21-30 with 748 cases (30.4\%) and patients between the ages of $31-40$ with 374 cases $(15.1 \%)$. Other than this there was 9 cases between the ages of $0-10(0.4 \%), 251$ cases between the ages of $41-50(10.2 \%), 104$ cases between the ages of 51-60 (4.2\%), 35 
cases between the ages of $61-70(1.4 \%), 6$ cases between the ages of $71-80(0,3 \%)$ and 2 cases between the ages of $81-90(0.1 \%)$.

In the distribution of penetrating stab wound according to seasons; there was 291 cases in may (11.8\%), 298 cases in july (12.1\%),
284 cases in june (11,5\%), 243 cases in march (9.9\%), 216 cases in september $(8.8 \%)$. In other months; there was 152 cases in january $(6.2 \%), 108$ cases in february (4.4\%), 247 cases in april (10\%), 260 cases in august (10.5\%), 137 cases in october $(5.5 \%), 109$ cases in november $(4.4 \%)$ and 119 cases in december $(4.8 \%)$.

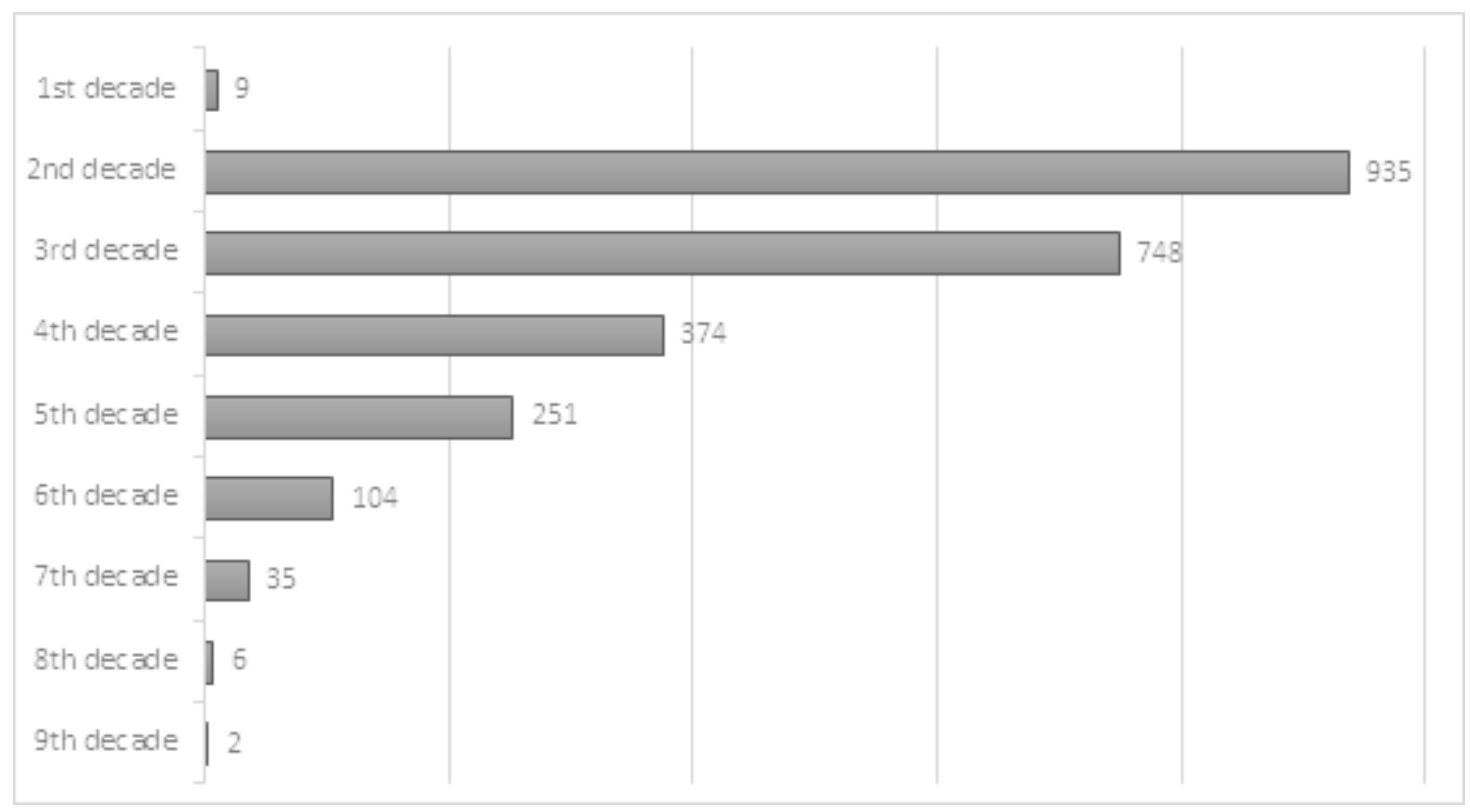

Figure 1: Distribution by Age Groups

When cases were examined in terms of exposure to life-threatening conditions and whatever can be solved with simple medical interventions or not; 284 cases $(11.5 \%)$ were found to be exposed to life-threatening conditions, 606 cases $(24.6 \%)$ were found to be injured in a way that could not be remedied by simple medical intervention (SMI) and 1574 patients (63.9\%) were found to be injured at a level that could be resolved by simple medical intervention.

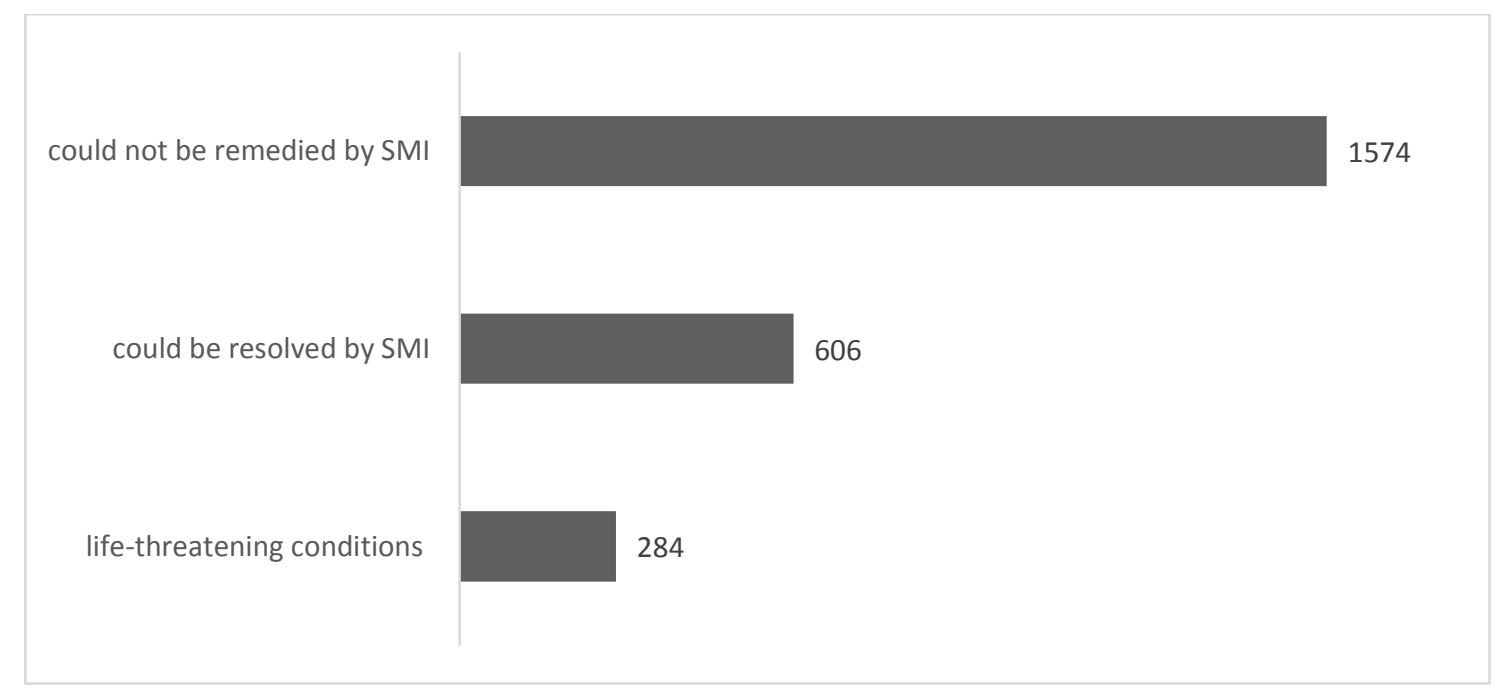

Figure 2: Distribution of lesions in terms of SMI and life threatening condition

When injuries were examined according to body regions; extremity injuries were in the first place with 1541 patients (62.5\%). Among these extremity injuries; it was observed that 671 patients (43.6\%) had upper extremity injuries and 870 patients (56.4\%) had lower extremity injuries. It was seen that extremity injury was followed by thorax injury which was seen in 408 patients (16.6\%), abdominal injury in 394 patients $(16 \%)$ and head and neck injury in 275 patients $(11.2 \%)$. 


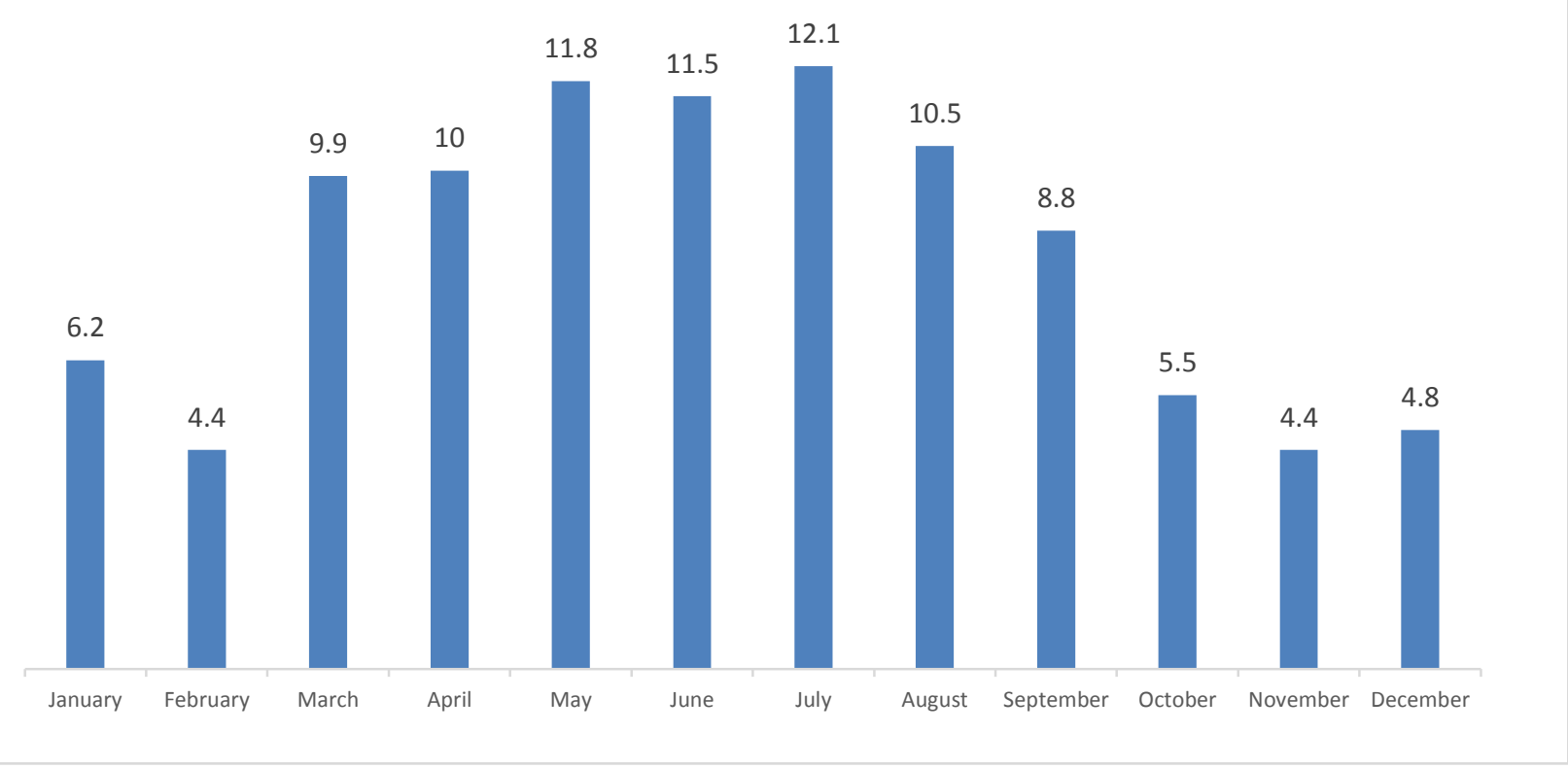

Figure 3: Distribution by month

When we deal with cases in terms of number of lesions; single lesion was in the first place which was seen in 1479 patients (60\%). This was followed by two lesions in 583 cases (23.7\%), 3 lesions in 218 cases $(8.8 \%)$ and 4 lesions in 84 cases (3.4\%). It was detected that 37 patients had 5 lesions, 23 patients had 6 lesions, 21 patients had 7 lesions, 9 patients had 8 lesions, 3 patients had 9 lesions, 3 patients had 11 lesions, 2 patients had 10 lesions, 1 patient had 12 lesions and 1 patient had 14 lesions.

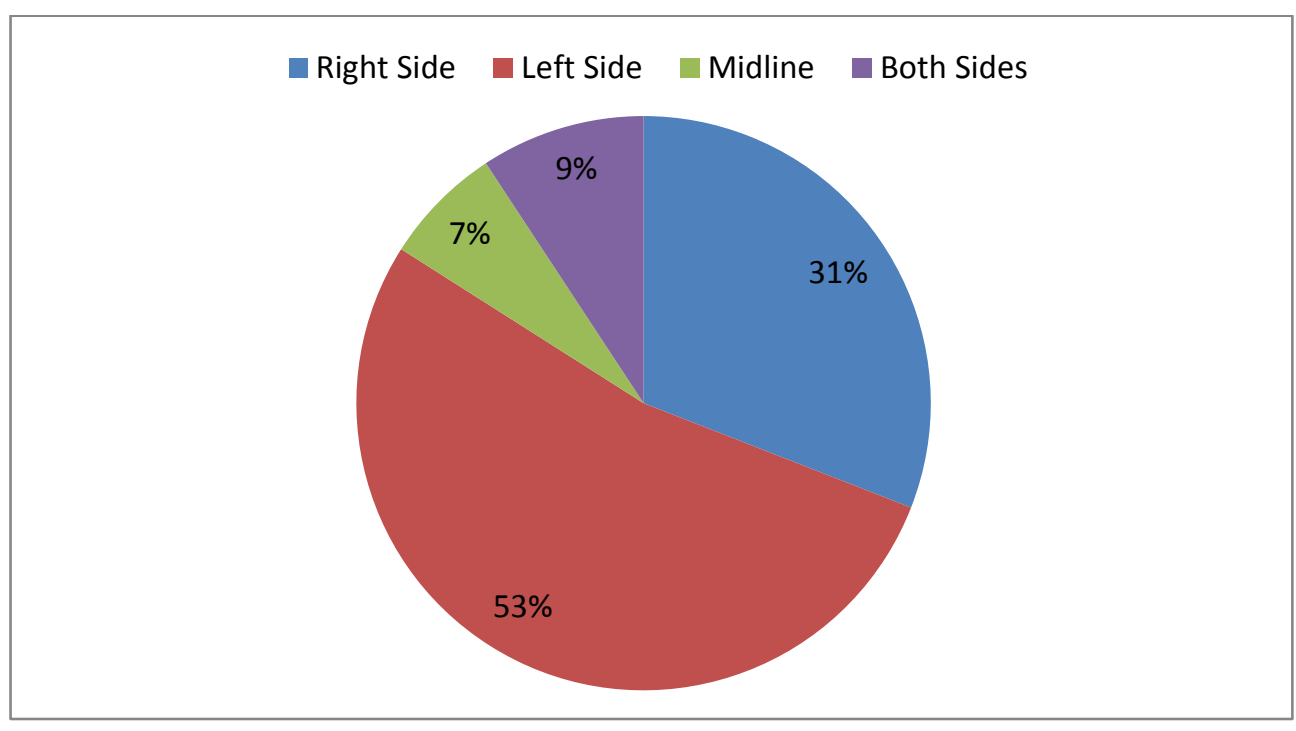

Figure 4: Injured Body Regions

While $53.1 \%$ (n:1308) of the cases were injured from the left side, $30.9 \%$ (n:762) of the cases were injured from the right side, $9.3 \%$ (n:228) of the cases were injured from on both sides and $6.7 \%$ (n:166) of cases were injured from midline.

When life-threatening injuries were handled according to body regions; thorax was in the first place with 118 cases (41.5\%) and this was followed by abdomen with 116 cases $(40.8 \%)$, extremity with 43 cases (15.2\%) and head-neck injuries in 7 cases (2.5\%).

In examination of injuries that can not be resolved by simple medical intervention; extremity injuries was seen in 419 patients $(69.1 \%)$, head-neck injuries were seen in 59 patients $(9.7 \%)$, abdominal injury was seen in 52 patients (8.6) and thorax injury was seen in 76 patients $(12.6 \%)$.

\section{Discussion}

The injuries and deaths caused by the cutting-drilling tool have an important place in the practice of forensic medicine. For this reason, it was thought that it would be useful to evaluate these cases from many angles. In our study a total of 2464 cases $(11.4 \%)$ with penetrating stab wound were observed among 21586 cases, who were consulted for exact report to the Forensic Medicine Department of Cukurova University Faculty of Medicine between 2013-2017. This ratio was found to be consistent with the values between $6.5-18.3$ reported in studies conducted in our country. ${ }^{[9-11]}$

In the studies conducted between 1993 - 1997; the ratio of penetrating stab wound was found to be between 2.2-6.5\% (12-14). This shows that the rate of injury with sharp objects is steadily increasing. 
Of the 2464 cases included in the study, 2219 (90\%) were male and $245(10 \%)$ were female. These values were found to be compatible with the same type of studies. ${ }^{[11,15-20]}$ However, the mean age of the cases was found to be 28.1. As a cause of this situation, young people and men are more likely to show violent acts in their daily lives compared to women and elderly people.

Most patients were found to be between the ages of 11-20 with 935 cases $(37.9 \%)$ and this was followed by patients between the ages of 21-30 with 748 cases (30.4\%). In similar studies, it was observed that the 21-30 age group came first, and the result obtained from our study was different from the literature. ${ }^{[20,21]}$ In a study of Arslan et al., in Adana in 2004; it was found that the 15-19 age group was in first place with $25.5 \%$, in agreement with our study.22 This shows that sharp object (knife) injuries in the Adana region have reached the highest level in the previous decade.

In our study, $56 \%$ of cases were found between April and August. When we look at the distribution of cases within the year; especially the increase in summer months, was found to be consistent with the literature. ${ }^{[1,20]}$

When an assessment was made according to the severity of the injuries; 284 cases $(11.5 \%)$ were exposed to life-threatening conditions. This ratio was close to the study of Arslan et al., in which the ratio was $10.6 \%$ but was significantly lower than the study of Dulger et al., and Altun et al., in which the ratios were $38.4 \%$ and $35.2 \%$, respectively. ${ }^{[20,22,23]}$

When injuries were examined according to body regions; extremity injuries were in the first place with 1541 cases $(62.5 \%)$. In lifethreatening injuries, thorax was in the first place with 118 cases (41.5\%), followed by abdominal injuries with 116 cases $(40.8 \%)$. When you looked at injuries that can not be eliminated by simple medical intervention; the ratio of extremity injuries increased to $69.1 \%$ (n:419). In this case if the attacker intends to kill the attacks are mostly drawn to the chest and abdomen area, or in cases where the purpose is to defend attacks are often drawn to the extremities

In our study, when number of lesions were examined; single penetrating stab wound was seen in 1479 cases $(60 \%)$ and the most seen penetrating stab wounds on a single person were 14 wounds. In the study of Altun et al., there was single lesion with a ratio of $31 \%$ and in the study of Arslan et al., this ratio was increased to $51.2 \%{ }^{[22,24]}$ In our study, the single lesion ratio was higher.

When injured body sides were examined; $53.1 \%$ (n:1308) of the cases were injured from the left side, $30.9 \%$ (n:762) of the cases were injured from the right side, $9.3 \%$ (n:228) of the cases were injured from on both sides and $6.7 \%$ (n:166) of cases were injured from midline.

Left side injuries can be explained as we studied with the majority of the society using the right hand. When injuries were examined according to body regions; extremity injuries were in the first place with 1541 cases $(62.5 \%)$. Among these extremity injuries; it was observed that 671 patients had upper extremity injuries and 870 patients had lower extremity injuries. Most of the non lethal injuries are seen in the left proxial lateral lower extremity and the gluteal region rather than the thorax or the abdominal region.

In conclusion, sharp objects are easy to access and can lead to murders and suicides, ranging from simple injuries to lifethreatening injuries. It is noteworthy that killing wounds are concentrated on thorax and abdominal areas whereas wounds for scaring the individual are more commonly seen in the lower extremities and most often at the left half of the body. In Adana, different from literature, the number of young people aged between 11 and 20 is high, young men constitute a risk group and there is an increasing number of penetrating stab wounds in the recent years which has become an important concern that needs to be taken into consideration and necessary measures should be taken.

\section{Limitations}

Retrospective design

\section{Conflict of interest}

None

\section{References}

[1] Gören S, Tıraşçı Y. Retrospective Evaluation of Deaths Dependent on Injury of Chest and Abdomen Penetrating Stab Wound (In Turkish). IIIrd Congress of Forensic Sciences Poster Presentations. The Bulletin of Legal Medicine 1999;4(3):123-126.

[2] Çoltu A, Durak D. The forensic autopsies of 109 death cases of wounds by sharp devices were examined by the Bursa Group Chairman of the Council of Forensic Medicine. Turkish Journal of Forensic Medicine 1992;8:61-63.

[3] Sarı H, Aşırdizer M, Okudan M, Cansunar N, Kolusayın Ö. Some survival criteria in penetrating cardiac injuries: evaluation of 444 autopsy cases and 105 survival cases. Turkish Journal of Forensic Medicine 1995; 11(1-4):1122.

[4] Henderson VJ, Smith RS, Fry WR, Morabito D, Peskin GW, Barkan H. Cardiacinjuries: Analysis of an unselectedseries of 251 cases. J. Trauma 1994; March 36(3):341-348.

[5] Sayın A, Özer M, Karaözbek Y, Erdağ A, Aktan K, Tüzün H. Vascular Injuries: A Study Of 208 Cases. Turkish Journal of Forensic Medicine 1987; 3(1-4):3444.

[6] Karagöz YM, Atılgan M, Karagöz(Demirçin) S, Demircan C. Evaluation of forensic autopsies in Antalya:1987-1993. 8. National Forensic Medicine Days, Poster Presenters' Book İstanbul:Dilek Ofset, 1995:149153.

[7] Özkök MS, Katkıcı U, Örsal M. Deaths Due To Stab Wounds: A Retrospective Study On Forensic Autopsies. Turkish Journal of Forensic Medicine 1992; 8(1-4):147154.

[8] Polat O, İnanıcı MA, Aksoy ME. Adli Tıp Ders Kitabı. Nobel Tip Kitabevi 1997.

[9] Tuğcu H, Özdemir Ç, Dalgıç M. Evaluation of the forensic reports documented at the Department of Forensic Medicine of Gülhane Military Academy of Medicine between 1995 and 2002 in the view of new Turkish Criminal Law. Gulhane Medical Journal 2005; 47: 102-105.

[10] Güven FMK, Bütün C, Beyaztaş FY. Evaluation of forensic cases admitted to Cumhuriyet University hospital. Meandros Medical and Dental Journal 2009; 10 (3): 23-28. 
[11] Karasu M, Baransel Isır A, Aydın N, Dülger E. Assesing The Forensic Reports Documanted By Forensic Medicine Department Of Medicine Faculty Of Gaziantep University Between 1998 And 2005 Years. Gaziantep Medical Journal 2009; 15(1): 10-15.

[12] Koç S, Öztek İ, Albek E, Lokman S. Analysis of 510 Forensic Cases Applied to GATA Haydarpaşa Training Hospital emergency department (In Turkish). 7. National Forensic Medicine Days, Poster Presenters' Book İstanbul:1993:147-156.

[13] Günaydın G, Demireli O, Şahin TK, Demirci Ş. Judicial reports given at the Selcuk University Emergency Department and their evaluation in terms of vital danger concept (In Turkish). 8. National Forensic Medicine Days, Poster Presenters' Book İstanbul: Dilek Ofset, 1995:271-275(In Turkish).

[14] Altun G, Azmak D, Yilmaz A, Y1lmaz G. The characteristics of the cases which admitted to Emergency Department of Trakya University Medical Faculty. The Bulletin of Legal Medicine 1997;2:62-66.

[15] Bilge Y, Kendi Ö. Investigation of 6227 Cases Due to Injunction and Traffic Accidents in Forensic Medicine (In Turkish). IIIrd Congress of Forensic Sciences Poster Presentations. The Bulletin of Legal Medicine 2000;5(1):26-31.

[16] Weeb E, Wyatt JP, Henry J, Busuttil A. A comparison of fatal with non-fatal knife injuries in Edinburgh. Forensic Science İnternational 1999;99:179-187.

[17] Alper B, Gülmen MK, Çekin N, Bilgin N, Salaçin S. Death Due to Intracranial Penetrating Stab Wounds:
Case Report. The Bulletin of Legal Medicine 1999;4(1):20-23.

[18] Fedakar R. Evaluation of Stab Wound Injuries Made in Autopsy Between 1997-2001 in Bursa(In Turkish). Annual Forensic Medical Meetings Book Antalya 2002:301-307(In Turkish).

[19] Türkmen N, Fedakar R, Çetin V, Durak D. The role of alcohol in deaths due to stab wound injuries. The Bulletin of Legal Medicine 2002;7(2):45-50.

[20] Altun G, Azmak D, Yilmaz A. Stab Wound İnjuries in Living Cases(In Turkish). IIIrd Congress of Forensic Sciences Poster Presentations. The Bulletin of Legal Medicine 2000;5(1):52-55.

[21] Sunay MY, Faruk IO. Evaluation Of Forensic Cases Applied To Emergency Department of Suleyman Demirel University Medical School Hospital Between 1999-2001. Turkish Journal of Forensic Medicine 2003; 17(1):47-53.

[22] Arslan M M, Akcan R, Hilal A, Kar H, Çekin N. The Evaluation of Stab Wound Cases Attended to Counc1l of Forensic Medicine in adana. Turkish Journal of Forensic Medicine 2005; 19(3):17-22.

[23] Dülger HE. Retrospectıve Evaluatıon of Stabbing Cases in Elazığ. Turkish Journal Of Forensic Medicine 1994;10:69-72.

[24] Altun G, Azmak D, Y1lmaz A. Deaths Due to Stab Wound Injuries (In Turkish). IIIrd Congress of Forensic Sciences Poster Presentations. The Bulletin of Legal Medicine 2000;5(1):44-46. 